\title{
References
}

Campion, M. C., \& Campion, E. D. (2018, April). Using text mining to identify and quantify strategically aligned applicant brands. Paper presented at the 33rd Annual Conference of the Society for Industrial and Organizational Psychology, Chicago, IL.

Campion, M. C., Campion, M. A., Campion, E. D., \& Reider, M. H. (2016). Initial investigation into computer scoring of candidate essays for personnel selection. Journal of Applied Psychology, 101, 958-975.

Rotolo, C. T., Church, A. H., Adler, S., Smither, J. W., Colquitt, A. L., Shull, A. C., ... Foster, G. (2018). Putting an end to bad talent management: A call to action for the field of I-O psychology. Industrial and Organizational Psychology: Perspectives on Science and Practice, 11(2), 176-219.

Song, Q., Wee, S., \& Newman, D. A. (2017). Diversity shrinkage: Cross-validating pareto-optimal weights to enhance diversity via hiring practices. Journal of Applied Psychology, 102, 1636-1657.

Uniform guidelines on employee selection procedures. (1978). Federal Register, 43, 38290-38315.

\section{I-O Psychologists Can Help Make Sure Your HiPos Aren't NoPos}

\author{
Lisa M. Finkelstein \\ Northern Illinois University \\ David P. Costanza \\ The George Washington University \\ Gerald F. Goodwin \\ US Army Research Institute for the Behavioral and Social Sciences
}

We agree with Rotolo et al.'s (2018) assertion that talent management is a space where the academic-practice gap in industrial and organizational (IO) psychology is quite cavernous and where the vulnerabilities to anti-I-O (AIO) are high. As researchers who began a journey a few years ago to explore the high potential (HiPo) identification process from the science perspective (largely inspired by Silzer \& Church, 2009), we echo the frustration that the current focal authors express with the science-side lag in this area. For us, what started as a question from a senior officer in the Army turned into the development of a theoretical model and the start of multilocation research lab designed to further the understanding and success of the HiPo identification process. Our objective is to share a bit of our journey that got us to this point and some lessons for others inspired by this focal article to become anti-anti-I-O (AAIO) warriors.

Lisa M. Finkelstein, Northern Illinois University; David P. Costanza, The George Washington University; Gerald F. Goodwin, US Army Research Institute for the Behavioral and Social Sciences.

Correspondence concerning this article should be addressed to Lisa M. Finkelstein, Northern Illinois University, DeKalb, Illinois 60115-2828. E-mail: lisaf@niu.edu 
To use the focal authors' terminology, we recognize that we hail from the pragmatic science camp. However, our initial efforts to track down solid, empirical HiPo research and to develop an understanding of the process made us aware of the canyonesque science-practice gap about HiPos. It also pointed to the need to partner with I-O psychology practitioners in the trenches as we formulated and then communicated our ideas. That is, given the science-practice gap in the HiPo area (and others of course) and to increase the likelihood that our work (and that of other scientists interested in this realm) would have an impact on organizations, it was clear we needed to develop our model using both research and practice-based concepts, conceptualizations, definitions, and approaches.

It actually took quite a while for that realization to strike. We originally approached the project like any other typical academic pursuit: (a) read literature, (b) create theoretically based, testable hypotheses, (c) design and run study, and so on. Facing a dearth of directly HiPo-related academic work to draw from, we engaged in a lot of extended conversations where we debated the literature, the issues, and our objectives for the project.

Our discussions were impacted by the make-up of our research team: two academics and an academically oriented practitioner. Our academic default was to draw from other psychological concepts with which we were more familiar, but having both academics and a practitioner on the team forced us to look at the questions from multiple perspectives. Further, because of the limited research in the area we were investigating, we solicited input and ideas from colleagues in academia, applied research, and consulting, each of whom gave us their unique and sometimes incompatible views about HiPos.

As a result of this input, we spent a lot of time bouncing back and forth between application and theory, debating how both theoretical and practical concerns should guide our thinking. At some meetings, we wandered too far into the theory realm (and down some interesting rabbit holes of psychology) whereas at others, we pinballed toward the world of practice, debating why organizations should care about what we were doing.

We were also constrained because, at times, we were thinking about how readily available, but less than optimal, Army data sets might impact our project. We often found ourselves stopping short and saying, "yeah, that would be really cool, but we can't test that here." Finally, during one extended watershed conversation, it dawned on us that we were starting to cut corners in theory development in order to suit an available data set instead of diving in headfirst to a more comprehensive and widely useful theory. So, we decided to focus our energies on theory first and empirical tests later. Even with that decision, we resolved to consider the practical application of our work as much as possible and strove to develop a theory that could 
actually be tested and the results of which might actually impact organizational policies and practices.

The result of this effort is a theoretically grounded and practically relevant model of high potential that just appeared in Personnel Psychology (Finkelstein, Costanza, \& Goodwin, 2018). The basic premise behind our efforts is that there is an important and largely ignored distinction between a person having potential and a person being designated as a HiPo. In line with what Rotolo et al. (2018) describe, those responsible for the HiPo designation process in organizations often ignore our long I-O psychology history, in particular the importance of valid assessment tools and methods to identify those who actually have potential.

Further, the methods that many organizations use and the situations in which they are embedded are riddled with a host of contextual factors that can lead to designation decisions that can be unrelated to actual potential. We felt the key to understanding HiPos was to start with what we know in I-O psychology about selection, training, leadership and other areas; cross it with what organizations are saying about HiPos and their needs; and propose a theoretically grounded but practically relevant model of high potential.

For example, one aspect of HiPo designation centers on biases in person perception, impression management, persuasion, and power differentialsfactors that may contribute to misdesignations. Some of this knowledge came from the academic realm (e.g., impression management from social psychology) and some from the world of practice (e.g., the idea that there is often an actual "list" of possible HiPos in organizations-a list that may or may not reflect individuals with key characteristics). From the latter, we learned that a person with actual high potential may be passed over for the list, or a person lacking potential but who has characteristics misinterpreted as potential indicators will receive this distinction and its many perks. Coming from this perspective, we strove to create a theoretical framing in terms of factors like impression management that could account for these practical observations.

We attempted to answer questions like "What happens in these circumstances when people with real potential are passed over?" "Why do those without it get designated regardless?" "What do organizations do with their HiPo designees and those not getting the coveted HiPo designation-or worse getting explicitly identified as not having potential ("NoPo")?" Our conclusion was that some level of leader success may still come to both designees and nondesignees, and for those on the list with potential and those without, but they are likely to be quite different paths to get there. This knowledge of social and organizational psychology informed by organizational practices is an example of a key weapon in the arsenal of the AAIO warrior. 
We explored several other areas that were implied or explicitly identified in organizational practices and also had relevance to a theoretical explanation of the process. These included understanding how nondesignated employees with potential might rise to the top through their own efforts to identify and engage in developmental opportunities. This implicated a number of individual factors, such as growth and development competencies and achievement motivation. We also learned that the formality of HiPo designation processes varies widely both within and between organizations, and hence the options for career development opportunities also vary widely. Consequently, we considered many possible paths for HiPo designees and nondesignees in development of the theoretical model.

A third area we considered centered on the very practical but unintended effects of instituting a formal HiPo designation process and program. More specifically, we felt we needed to consider how being formally and publicly designated as HiPo affect the motivation of the designees, as well as the converse: How would the motivation of those not designated be affected? The fact that benchmarking studies showed widely varying organizational practices with respect to designation and motivation suggested that there was no agreed upon set of HiPo practices. Hence, each of these questions has significant implications for practice and are ripe for empirical study, both in the lab and in applied settings.

Though there are aspects of these areas that are well founded in existing I-O psychology research, they are largely untested in the area of HiPo designation with actual organizational members. There are also aspects of potential and organizations actual HiPo designation process that are not discussed at all in the academic literature but that can be extracted from applied writings, organizational best practices, and consulting interventions. Some of the issues we came across when doing so are in need of a more thorough causal understanding and could benefit from laboratory research, spearheaded and carried out by academics with the consultation of practitioners to enhance utility and ecological validity. Other questions may require a longitudinal perspective best gleaned from archival data derived from existing organizational HiPo programs and applied research and practice efforts. Organizations that are willing to work in partnership with outside I-O psychology researchers in the spirit of action research to design, test, and evaluate different methods of HiPo designation could go a long way to contribute to strong science that is actionable and can stand up against the AIO forces.

Rotolo et al. (2018) speculated that readers may be critical of the generality of their suggestions for changing what is broken with talent management and go on to suggest a Society for Industrial and Organizational Psychology (SIOP) taskforce so that we can use our own talents systematically to fix this practice. This may be a worthwhile pursuit at a macro level and may be one 
valuable path toward systematic change. However, each of us as individual I-O psychologists-both practitioners and academics-who wish to deflect an AIO bias and bring power back to I-O can do something about it now.

Although we are each likely guilty of activating our stereotypes about one another at least on occasion (from those out-of-touch academics to those nonrigorous practitioners), it is also likely true that each of us has friends on the other side of the science-practice gap. We went to grad school together. We taught each other or supervised each other in internships. We met at a SIOP party over a few cocktails. Whatever it is, we likely know each other, like each other, and have the ability to forge real connections to combine strengths to combat the AIO forces in the emerging and frontier issues. We are quite confident that our scientist-practitioner collaboration in the area of HiPos made our model more comprehensive, sound, testable, and yes, applicable than it would otherwise have been if we did not undertake a conscious effort bridge the canyon. We suggest such efforts are one way of countering the AIO trends that threaten our field.

\section{References}

Finkelstein, L., Costanza, D., \& Goodwin, G. (2018). Do your HiPos have potential? The impact of individual differences and designation on leader success. Personnel Psychology, 71, 3-22. doi: $10.1111 /$ peps. 12225

Rotolo, C. T., Church, A. H., Adler, S., Smither, J. W., Colquitt, A. L., Shull, A. C., ... Foster, G. (2018). Putting an end to bad talent management: A call to action for the field of I-O psychology. Industrial and Organizational Psychology: Perspectives on Science and Practice, 11(2), 176-219.

Silzer, R., \& Church, A. H. (2009). The pearls and perils of identifying potential. Industrial and Organizational Psychology: Perspectives on Science and Practice, 2, 377-412. doi: 10.1111/j.17549434.2009.01163.x. 